TITLE:

\title{
Japanese monkeys (Macaca fuscata) spontaneously associate alarm calls with snakes appearing in the left visual field.
}

\section{AUTHOR(S):}

Shibasaki, Masahiro; Nagumo, Sumiharu; Koda, Hiroki

\section{CITATION:}

Shibasaki, Masahiro ...[et al]. Japanese monkeys (Macaca fuscata) spontaneously associate alarm calls with snakes appearing in the left visual field.. Journal of comparative psychology 2014, 128(3): 332-335

\section{ISSUE DATE:}

2014-08

URL:

http://hdl.handle.net/2433/189546

\section{RIGHT:}

C2014 American Psychological Association; This article may not exactly replicate the final version published in the APA journal. It is not the copy of record.; この論文は著者最終稿 です。内容が印刷版と異なることがありますので、引用の際には出版社版をご確認ご利 用ください。This is the Accepted Author Manuscript. Please cite only the published version. 
1 Running Head: Spontaneous association between alarm calls and snakes in monkeys

2

3 Short communications to Journal of Comparative Psychology

4

5 Japanese monkeys (Macaca fuscata) spontaneously associate alarm calls with snakes appearing in

6

the left visual field

7 
9 Many socially living animals are sensitive to a potential predator as part of their anti-predator

10 strategy. Alarm calls function to deter predators and to help other group members detect danger.

11 The left visual field is involved in detection of potential threats or predators in many vertebrates, but

12 it is unclear how alarm calls influence visual detection of a potential predator. Here, we

13 experimentally examined how alarm calls spontaneously influence the search for pictures of a

14 potential predator in captive Japanese macaques. We used an audiovisual preferential-looking

15 paradigm by presenting pictures of a snake and a flower simultaneous with either a recording of

16 alarm calls or contact calls. We found no difference in gaze duration between the two picture types

17 when playing back contact calls. Monkeys looked significantly longer at pictures of snakes than at

18 those of flowers when alarm calls were played back if the snake pictures were presented on the left

19 side of the monkey's visual field, indicating right hemispheric bias during processing of predator

20 representations. This is the first laboratory demonstration of auditory enhancement of visual

21 detection of predators in the left visual field in animals, which will contribute to a better

22 understanding of alarm call studies conducted in the wild.

23 Keywords: anti-predator strategy; visual lateralization; alarm call; snake fear; nonhuman primates 
Human and nonhuman primates appear extremely sensitive to biologically threatening stimuli

such as snakes (LoBue, Rakison, \& DeLoache, 2010). Humans are easily conditioned to react to

pictures of snakes, and this conditioned fear of snakes is resistant to extinction (see Ohman \&

Mineka, 2001, 2003 for a review). Similar to humans, laboratory-reared rhesus monkeys are

quickly conditioned to fear snakes after watching videotapes of monkeys being frightened by

snakes (Cook \& Mineka, 1990). Humans and nonhuman primates also detect snakes faster than they

detect neutral stimuli (e.g., flowers) during visual search tasks (LoBue et al., 2010). Even young

children and lab-reared monkeys with no experience with snakes are faster to detect snakes than

flowers (LoBue \& DeLoache, 2008; Shibasaki \& Kawai, 2009).

34 primates and many other vertebrates (see Rogers \& Andrew, 2002; Rogers, Vallortigara, \& Andrew,

352013 for reviews). Horses react more strongly to a frightening stimulus when it is presented in the

36 left visual field (Austin \& Rogers, 2007), and horses use the left eye to view a potential threat or

37 predator (Farmer, Krueger, \& Byrne, 2010). The stripe-faced dunnart showed the higher reactivity

38 when the subjects were presented with a model snake on their left side (Lippolis, Westman,

McAllan, \& Rogers, 2005), thus indicating specialization of the right side of the brain in controlling

Gelada baboons direct more aggressive responses to conspecifics on their left side than they do to 
47 representation of potential predators and further evoke animal escapes. Despite clear evidences for

48 association of predator presence and alarm calls, it has been unclear how alarm calls influence

49 detections of potential predators. For the learning of alarm calls, experiences like observing

50 demonstrators would be necessary for nonhuman primates (e.g., Campbell \& Snowdon, 2009).

51 The aim of this study was to investigate how alarm calls spontaneously influence detection of

52 potential predator pictures by captive Japanese macaques, particularly if they are presented in the

53 left visual field. We assessed this with an audiovisual preferential-looking paradigm in which

54 Japanese macaques were simultaneously presented with alarm calls and pictures of a predator.

55 Audiovisual preferential-looking paradigms have been used to investigate matching ability in the

56 auditory and visual sense modalities in animals (Ghazanfar \& Logothetis, 2003) and human infants

57 (Kuhl \& Meltzoff, 1982). In a typical task, pairs of images (or movies) are presented to subjects in

58 conjunction with an auditory stimulus. The rationale is that if the auditory stimulus has the power to

59 evoke recall of an associated mental representation or emotion, then subjects are expected to look

60 longer at the matching visual stimulus relative to a control stimulus.

61 In our experiments, we paired pictures of snakes and flowers with the Japanese macaques'

62 alarm and contact calls. If alarm calls emotionally enhance visual detection of a potential predator,

63 biased visual detection of threatening stimuli would occur more clearly.

64

Method

Subjects. We used 16 female Japanese macaques (Macaca fuscata) aged 2-6 years. All were

67 born into social groups housed in outdoor enclosures at the Primate Research Institute, Kyoto

68 University and naïve to seeing snakes. 
$70600 \mathrm{H}$ ) that was positioned in a sound attenuating chamber (RE-246, TRACOUSTICS). Three sides

of the experimental box were covered with transparent polycarbonate boards, and the other was the cage gate. Subjects were tested individually in the experimental box using a 22 -inch LCD screen (ProLite E2208HDS, IIYAMA, Tokyo, Japan) mounted on the experimental box, which enabled subjects to look at the monitor. The screen was connected to a computer placed outside the sound chamber for stimulus presentation. The screen resolution was set to $1600 \times 800$ pixels. A small 8.5-mm 1-in -pinhole infrared-sensitive CCD camera $(40 \times 25 \times 36 \mathrm{~mm}$, ITC-401, ITC, Tokyo, Japan) placed at the center of the monitor was connected to a TV screen (LC-22K5, SHARP, Japan) outside the sound chamber for gaze analysis and to a video camera (GZ-MG840-A, Victor, Japan) to record the subject's behavior during experiments. An active speaker (SRS-Z100, Sony, Tokyo, Japan) placed under the center of the LCD screen was used to deliver the playback stimuli.

Visual Stimuli. We used two snake and two flower pictures as visual stimuli. The pictures, which were available from the internet (http://www.pitt.edu/ mcs2/herp/SoNA.html, http://www.flowerpictures.net/flower_pictures.htm), and used in previous studies (Shibasaki \& Kawai, 2009). The pictures were reformatted to $300 \times 400$ pixels. The snakes used for stimuli were species which wild Japanese macaques never naturally see in the forest in order to neglect the possible effect of "innate" reactions to specific snake species which wild macaques can see. The average luminance and contrast were equalized across all stimuli with Adobe Photoshop CS5. Auditory Stimuli. We used an alarm call and a contact call series as auditory stimuli (see online supplementary Figure S1). Both calls were recorded from free-ranging Japanese macaques by HK in 2006. Alarm calls of Japanese macaques were defined as being of only a single type given to dogs, snakes and other potential predators (Green 1975). Contact calls are frequently exchanged among group members during the movement to maintain their cohesion (Koda, 2004). Both 
93 playback stimuli consisted of a series of three calls delivered at the same rate over a total duration of

$9410 \mathrm{~s}$. Calls were edited to match the maximum intensities between calls using Adobe Audition 2.0.

Procedure. Prior to each trial, we displayed a fixation cross in the center of the screen to draw

the monkeys' attention. Once this occurred, the experimenter simultaneously displayed pictures of a positions of paired stimuli. Consequently four trials were performed for each subject monkey. honestly significant difference test. Significance levels were all set to $p<.05$. 
University).

Results

Prior to analysis, we performed Levene test to check the normal distribution of the data, and

confirmed that our data were normally distributed, $p>0.13$. The repeated-measures ANOVA

revealed a significant main effect of stimulus type, $F(1,30)=10.13, p<.005, \eta_{p}{ }^{2}=.25$, but not of

call type, $F(1,30)=1.01, p=.32, \eta_{p}{ }^{2}=.03$, and position, $F(1,30)=3.14, p=.09, \eta_{p}{ }^{2}=.09$. More

importantly, a three-way interaction effect was found in looking time (LT), $F(1,30)=4.70, p<.05$,

$\eta_{p}{ }^{2}=.14$. To examine how three main effects interacted with each other, post-hoc comparisons were performed. The post-hoc analyses further revealed that this was due to a significant difference in

looking time between the snake and flower pictures in the alarm condition (mean LT $\pm 95 \%$

confidence interval, snake: $52.50 \pm 15.37$ frames; flower: $21.44 \pm 10.71$ frames, $p=.02$, Figure 1), but not in the contact-call condition (snake: $39.50 \pm 16.93$ frames; flower: $23.69 \pm 8.93$ frames, $p$ $=.65$, Figure 1), when snake pictures were presented on the left, indicating that monkeys looked significantly longer at pictures of snakes when they heard alarm calls and the snake picture was presented in the left visual field. In contrast with the condition where the snake picture appears on the left side, there is no significant difference in looking time between the snake and flower pictures in both the alarm condition (snake: $37.75 \pm 12.44$ frames; flower: $40.81 \pm 12.32$ frames, $p=.99$, $p=.36$, Figure 1), when snake picture was presented on the right side.

\section{Discussion}


139 alarm calls enhance looking at predator images. Subjects looked longer at pictures of snakes when

140 they heard alarm calls compared with when they heard contact calls, suggesting specialized

141 cognitive traits for audio-visual processing of fear related stimuli. This would agree with the notion

142 that the amygdala responds audio-visually to fear related stimuli (Kuraoka \& Nakamura,

143 2007).Furthermore, our study showed left-side bias during snake picture processing under the alarm

144 call condition, suggesting right-hemispheric neural bias. Right-hemisphere dominance in amygdala

145 processing has also been found in humans during processing of fear-relevant stimuli such as angry

146 human faces (Gainotti, 2012). Equally relevant studies have found a left-eye bias in response to

147 frightening stimuli in vertebrates, including fish, frogs, lizards, birds, rodents, dogs, horses, and

148 primates (Kaplan \& Rogers, 2013; Vallortigara \& Rogers, 2005 for review). Particularly, recent

149 studies in dogs have revealed the biased monitoring reactions to social stimuli. The experiment

150 using a head-orienting procedure showed that dogs turned their head to the right side (left

151 hemisphere) in response to conspecific vocalizations, but to the left side in response to the sound of

152 the thunderstorm (Siniscalchi, Quaranta, \& Rogers, 2008). Dogs turned preferentially their head to

153 the left side in response to the silhouettes of snakes (Siniscalchi, Sasso, Pepe, Vallortigara, \&

154 Quaranta, 2010). The two studies suggests dog's biased processing in right hemisphere for

155 audio-visual fear related stimuli. The similar right hemisphere dominance has been found in

156 primates. The common marmosets displayed right-eye preferences for viewing a piece of preferred

157 food (Hook-Costigan \& Rogers, 1998). However, when the marmosets viewed a model snake, they

158 displayed increased arousal and the eye preferences shifted away from a preference for the right eye

159 to a left-eye preference (Hook-Costigan \& Rogers, 1998). Our findings are in line with these

160 previous findings, suggesting a hemispheric bias in the neural mechanisms of emotional processing,

161 particularly fear processing. 

snake fear (Mineka, Davidson, Cook, \& Keir, 1984). According to this "preparedness theory" (Seligman, 1971), some natural stimuli are easier to condition to fearful responses than others, suggesting that animals are evolutionarily prepared to learn some associations more rapidly and effectively than others. Experiments with laboratory-reared monkeys naive to snakes have shown that they rapidly acquire a fear of snakes by observing other monkeys showing fear responses to snakes (Mineka \& Öhman, 2002). Such learning is strong and persistent (Cook, Mineka, Wolkenstein, \& Laitsch, 1985; Mineka et al., 1984), even if the fearful model monkey is shown on video (Cook \& Mineka, 1990). Of particular importance is that our subjects reared in captivity were naive to snakes. In conclusion, monkeys appear to have an innate sensitivity to snakes, and alarm calls appear to be particularly suited to this process.

We showed spontaneous lateralized looking at a predator evoked by alarm calls in monkeys, suggesting audiovisual correspondence during processing of emotional stimuli, demonstrated by the association between predator images and alarm calls. Here we hypothesize that learning a fear of snakes requires experience, whereas the association between alarm calls and potential predators is innate. However, we should acknowledge some research limitations of limited set of stimuli used here. The further study with a large number of stimulus sets would be necessary to generalize our findings. Furthermore, we need to compare the snake pictures to other pictures instead of flowers and replicate our findings to reject the possibility that the results might just be based on the lack of preference for snakes when presented on the right side with alarm call. 

monkeys, and for help with data acquisition and coding. We are grateful to Klaus Zuberbuhler for

188 his comments on our studies. This study was supported by JSPS Grant-in-Aids for Scientific

189 Research (B, \#22330200, \#25285199) to Nobuyuki Kawai (HK joined as co-PI), a JSPS fellowship

190 (\#23.5358) to MS, and the Young Researcher Overseas Visit Program of Kyoto University. 
Austin, N. P., \& Rogers, L. J. (2007). Asymmetry of flight and escape turning responses in horses. Laterality, 12, 464-474.

Campbell, M. W., \& Snowdon, C. T. (2009). Can auditory playback condition predator mobbing in captive-reared Saguinus oedipus? International Journal of Primatology, 30, 93-102.

Casperd, J. M., \& Dunbar, R. I. M. (1996). Asymmetries in the visual processing of emotional cues during agonistic interactions by gelada baboons. Behavioural Processes, 37, 57-65.

Chapelain, A. S., \& Blois-Heulin, C. (2009). Lateralization for visual processes: eye preference in campbell’s monkeys (Cercopithecus c. campbelli). Animal Cognition, 12, 11-19.

Cook, M., Mineka, S., Wolkenstein, B., \& Laitsch, K. (1985). Observational conditioning of snake fear in unrelated rhesus monkeys. Journal of Abnormal Psychology, 94, 591-610.

Cook M., \& Mineka, S. (1990). Selective associations in the observational conditioning of fear in rhesus monkeys. Journal of Experimental Psychology: Animal Behavior Processes, 16, 372-389.

Farmer, K., Krueger, K., \& Byrne, R. W. (2010). Visual laterality in the domestic horse (Equus caballus) interacting with humans. Animal Cognition, 13, 229-238.

Gainotti, G. (2012). Unconscious processing of emotions and the right hemisphere. Neuropsychologia, 50, 205-218. 423, 937-938. 
214 Hook-Costigan, M. A., \& Rogers, L. J. (1998). Eye preferences in common marmosets (Callithrix 215 jacchus): Influence of age, stimulus, and hand preference. Laterality, 3, 109-130.

216 Kaplan, G., \& Rogers, L. J. (2013). Stability of referential signalling across time and locations: testing alarm calls of Australian magpies (Gymnorhina tibicen) in urban and rural Australia and in Fiji. PeerJ 1:e112 http://dx.doi.org/10.7717/peerj.112

219

220

221

222

223

224

225

226

227

228

229

230

231

232

233

234

235

Koda, H. (2004). Flexibility and context-sensitivity during the vocal exchange of cool calls in wild japanese macaques (Macaca fuscata yakui). Behaviour, 141, 1279-1296.

Kuhl, P. K., \& Meltzoff, A. N. (1982). The bimodal perception of speech in infancy. Science, 218, $1138-1141$.

Kuraoka, K., \& Nakamura, K. (2007). Responses of single neurons in monkey amygdala to facial and vocal emotions. Journal of Neurophysiology, 97, 1379-1387.Lippolis, G., Bisazza, A., Rogers, J. \& Vallortigara, G. (2002). Lateralization of predator avoidance responses in three species of toads. Laterality, 7, 163-183.

Lippolis, G., Westman, W., McAllan, B. M., \& Rogers, L. J. (2005). Lateralization of escape responses in the striped-faced dunnart, Sminthopsis macroura (Dasyuridae: Marsupalia). Laterality, 10, 457-470.

LoBue, V., \& DeLoache, J. S. (2008). Detecting the snake in the grass. Psychological Science, 19, 284-289.

LoBue, V., Rakison, D. H., \& DeLoache, J. S. (2010). Threat perception across the life span: Evidence for multiple converging pathways. Current Directions in Psychological Science, 19, 375-379.

Mineka, S., Davidson, M., Cook, M., \& Keir, R. (1984). Observational conditioning of snake fear in rhesus monkeys. Journal of Abnormal Psychology, 93, 355-372. 
237 Mineka, S., \& Öhman, A. (2002). Phobias and preparedness: The selective, automatic, and encapsulated nature of fear. Biological Psychiatry, 52, 927-937.

Öhman, A., \& Mineka, S. (2001). Fears, phobias, and preparedness: Toward an evolved module of fear and fear learning. Psychological Review, 108, 483-522.

241

Öhman, A., \& Mineka, S. (2003). The malicious serpent: Snakes as a prototypical stimulus for an

Rogers, L. J., Vallortigara, G., \& Andrew, R. J. (2013). Divided brains. Cambridge: Cambridge University Press.

Sato, A., Koda, H., Lemasson, A., Nagumo, S., \& Masataka, N. (2012). Visual recognition of age

Seligman, M. E. P. (1971). Phobias and preparedness. Behavior Therapy, 2, 307-320.

251

252

253

254 class and preference for infantile features: implications for species-specific vs universal cognitive traits in primates. PLoS ONE, 7, e38387.

Shibasaki, M., \& Kawai, N. (2009). Rapid detection of snakes by Japanese monkeys (Macaca fuscata): An evolutionarily predisposed visual system. Journal of Comparative Psychology, $123,131-135$.

Siniscalchi, M., Quaranta, A., \& Rogers, L. J. (2008). Hemispheric specialization in dogs for processing different acoustic stimuli. PLOS ONE, 3: e3349.

Siniscalchi, M., Sasso, R., Pepe, A. M., Vallortigara, G., \& Quaranta, A. (2010). Dogs turn left to emotional stimuli. Behavioural Brain Research, 208, 516-521.

Vallortigara, G., \& Rogers, L. J. (2005). Survival with an asymmetrical brain: advantages and disadvantages of cerebral lateralization. Behavioral and Brain Sciences, 28, 575-588. 
260 Zuberbuhler, K. (2003). Referential signaling in non-human primates: Cognitive precursors and

261 limitations for the evolution of language. In Advances in the Study of Behavior, 33 (pp.

262 265-307).

263 
264 Figure legend

265 Figure 1. Looking duration of Japanese macaques at images of snakes and flowers presented to the

266 left or right visual field while hearing recordings of conspecific alarm calls or contact calls (means

$267 \pm 95 \%$ confidence intervals)

268 Online Supplementary Figure legend

Figure S1. Sound spectrogram of calls used for stimuli in the experiments. 
Figure 1
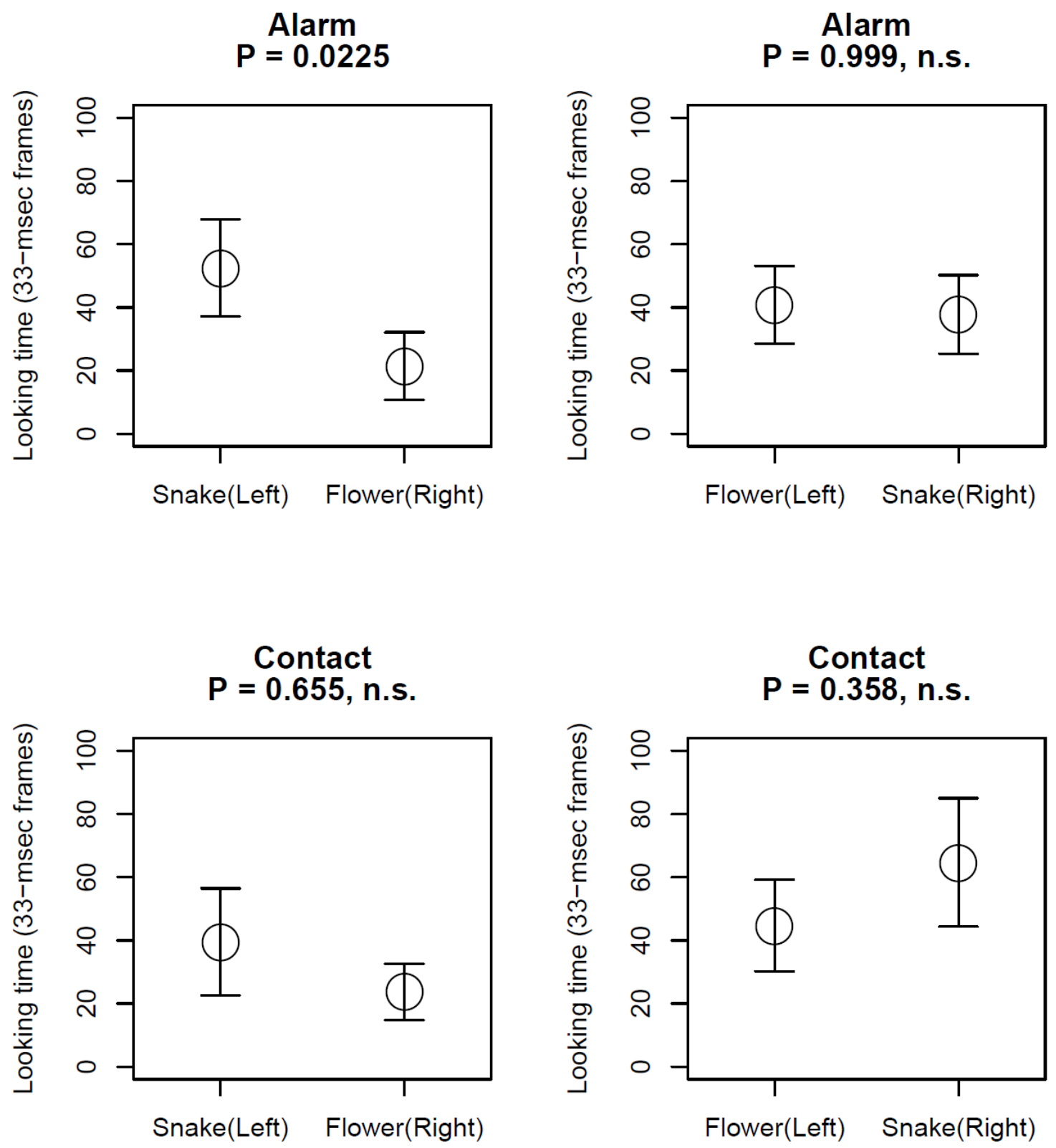
Online supplementary material

\section{Figure S1}
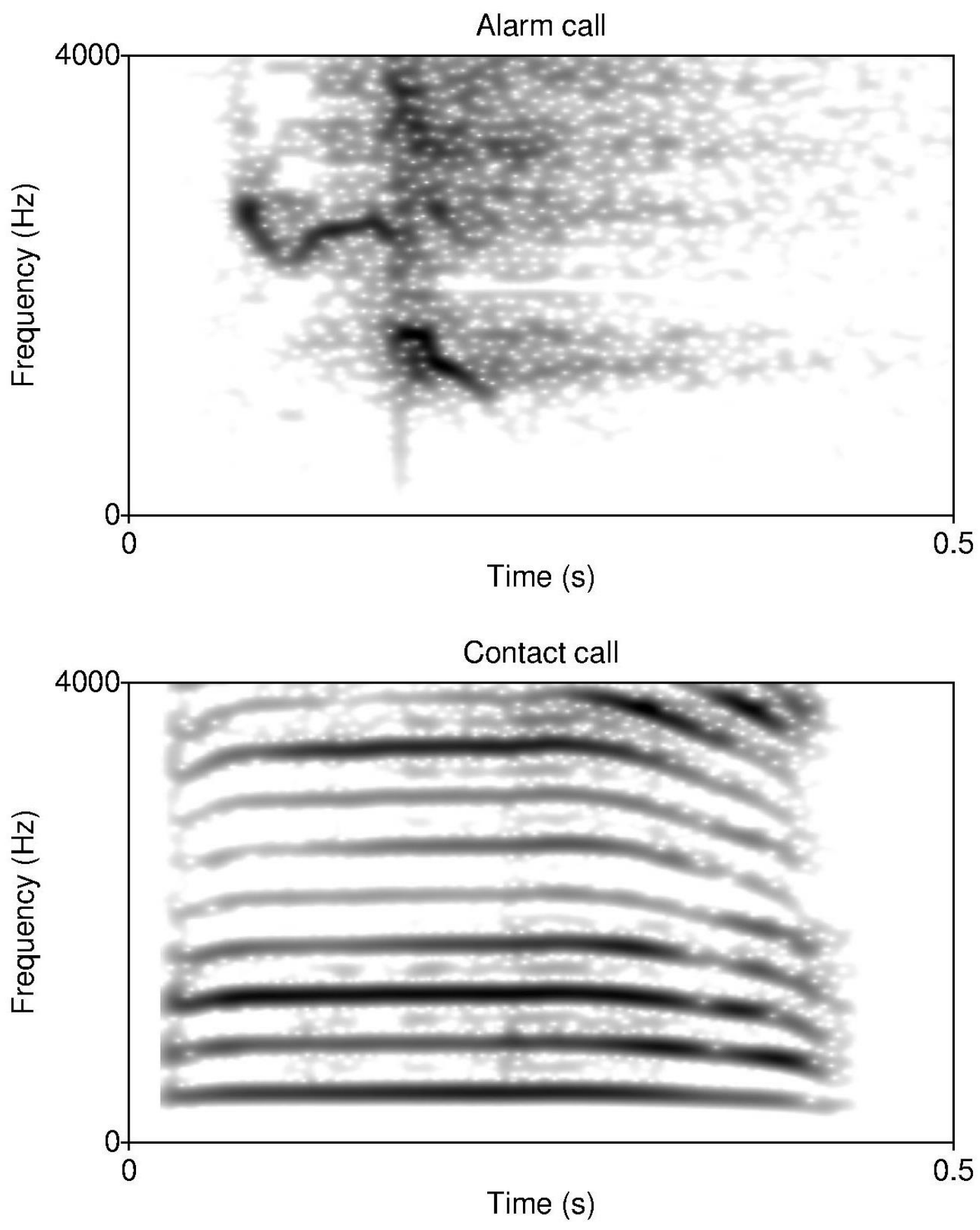